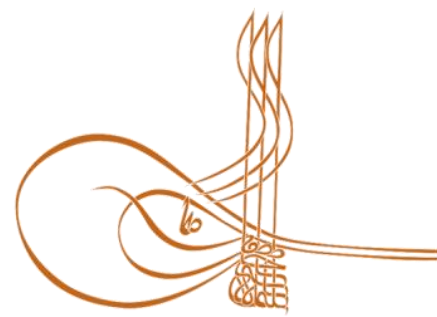

www.turkishstudies.net/economy
Turkish Studies - Economics, Finance, Politics

eISSN: $2667-5625$

Research Article / Araștırma Makalesi

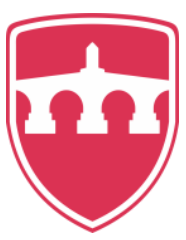

INTERNATIONAL

BALKAN

UNIVERSITY

Sponsored by IBU

\title{
Çalışanların Kişisel Değerleri, Algıladıkları Örgütsel Destek ve İşten Ayrılma Niyetleri Arasındaki Etkileşim
}

\author{
The Interaction Between Personal Values of Employees, Perceived Organizational Support and \\ Intention to Quit
}

\author{
Esra Aydın Göktepe* - Pervin Tunç** - Osman Yıldırım ${ }^{* * *}-$ Hakan Tetik $^{* * * *}$
}

\begin{abstract}
Perceived organizational support is effective for the employee to show positive attitude towards the enterprise. High levels of perceived organizational support of employees will reduce anti-productivity behaviors and attitudes. Personal values provide a framework for the attitudes that individuals will develop in their social and business lives. The intention to leave, which is an anti-productive behavior, brings high personnel costs to businesses. According to this, in research the relationship between organizational support and personal values is studied for having a low employees' turnover intention. In research quantitative research methodology is used. To collect data, 363 people who work in health sector was reached by survey. The result of the research is that turnover intention was effected from Organizational Support $(S)(.244 ; \mathrm{p}<0.05)$ and Personal Inner Value $(-1.858 ; \mathrm{p}<0.05)$. There is no effect of Personal Outer Values on turnover intention. It is determined that there is negative relationship effect between turnover intention and Personal Inner Values; happiness, personal development, enjoying life, self-respect and sense of achievement. It is concluded that there is negative relationship between Idea of Leaving the Job and Organizational Support. At the end of the research, it was suggested that organizational support should be provided to managers and Human Resources
\end{abstract}

\footnotetext{
* Dr. Öğr. Üyesi, İstanbul Arel Üniversitesi, İktisadi İdari Bilimler Fakültesi, İşletme Bölümü Asst. Prof. Dr., İstanbul Arel University, Faculty of Economics and Administrative Sciences, Departman of Business Administration 
specialists working in health sector in order to reduce their intention to quit. Since the support that the employee will need will be tailor-made, it is one of the recommended methods for managers to determine the needs of their employees correctly. The determining role of personal values in determining employee needs will also be an important clue in providing accurate data to managers.

Structured Abstract: It is seen that personal values are effective in the attitudes and behaviors developed by individuals towards the organization in the structure and functioning of organizations. Since manpower will provide a competitive advantage for organizations, retention of competent employees and low turn-over rate become desirable for organizations. Perceived organizational support is defined as the extent to which organizations attach importance to the happiness and welfare of employees and to what extent the individual feels this importance. Perceived organizational support studies, types of support are discussed under the headings such as emotional, instrumental, informational and esteem, career, material support. Values also provide a prediction of attitudes and behaviors. The intention to leave may become predictable and directable by determining the values of the person. As a disadvantageous situation, the tendency to leave the job has taken its place in the literature as an interesting subject in organizational psychology and management-organization literature as it is a cost-increasing result especially for enterprises. Determining the reasons and the variables associated with the tendency to leave, which has a direct impact on costs such as hiring, placement, training, compensation of errors, compensation and payments paid after the layoffs and the effect of the survivors' syndrome after the layoffs, necessitates the determination of the variables and related variables.

The data collection tool of the study has been determined as a questionnaire and the sector where the research will be conducted is limited to the health sector. The study included 368 volunteer participants in the health sector. Organizational Support Scale (POS) developed by Eisenberger et al. (1986) is revised which consisted of 6 items with a short version of the 16-item scale, revised in 2002, was used in Tokgöz's (2002) study. A 3-item Turnover Intention Scale developed by Mobley, Horner and Hollingsworth (1978; 410) was used in the study. Kahle (1983) developed 8 basic values, 8-item LOV scale was used. Questionnaire responses of the participants were analyzed using SPSS for Windows 22.00 and AMOS 22.0 program and then edited and interpreted in the light of literature. The confirmatory factor analyzes of the scales used in the study were performed in the AMOS program.52.3\% of the participants were women. $47.1 \%$ of the participants were between 25-29 years of age and 86.8\% were university graduates. In addition, the ratio of those with 1 to 5 years of work experience was $47.1 \%$

In Table 1, "Organizational Support"(.737) value of the scales applied to the participants within the scope of the research was very reliable. The "Intention to Leave" scale and the" Personal Values "scale are located in (.879) and (.916) with high reliability. The first dimension "Internal Values" consists of 5 items and is highly reliable with Cronbach's Alpha value (.884), while "External Values oluş consists of 3 items and is highly reliable with Cronbach's Alpha value (.775)

As a result of the confirmatory factor analysis given in Table 2, $\mathrm{x} 2 / \mathrm{df}$ value (1.812) was found to be significant. According to Table 2, GFI(.997),CFI (.996), SRMR (.0166), RMSEA (.047. These results show that the scale is significant.

Figure 1 shows the confirmatory factor analysis of the organizational support scale. Factor loading of the scale dimensions ranged from .054 to .81

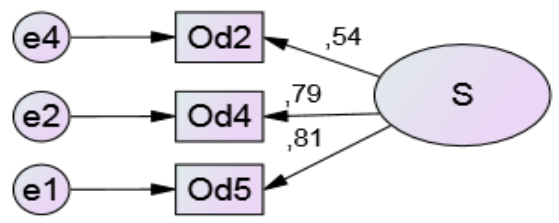

Figure 1. Confirmatory Factor Analysis of Perceived Organization Scale 
Figure 2 shows the confirmatory factor analysis of the turnover intention scale. Factor loading of the scale dimensions ranged from .074 to .94 .

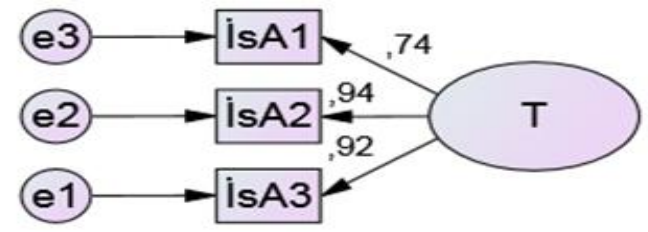

Figure 2. Confirmatory Factor Analysis of Turnover Intention Scale

Figure 3 shows the confirmatory factor analysis of the turnover intention scale. Factor loading of the scale dimensions ranged from .069 to .92 .



Figure 3. Confirmatory Factor Analysis of Personel Traits Scale

Figure 4 shows the path analysis obtained as a result of structural equation modeling of the scales. As a result of structural equation model, $\mathrm{x} 2 / \mathrm{df}(1.513)$ and $(\mathrm{p}<0.05)$ were obtained. $\mathrm{n}$ addition, structural equation model good fit index values (RMSEA (0.051), GFI (0.930), CFI (0.979) and SRMR (0.0459) were obtained within acceptable limits. 


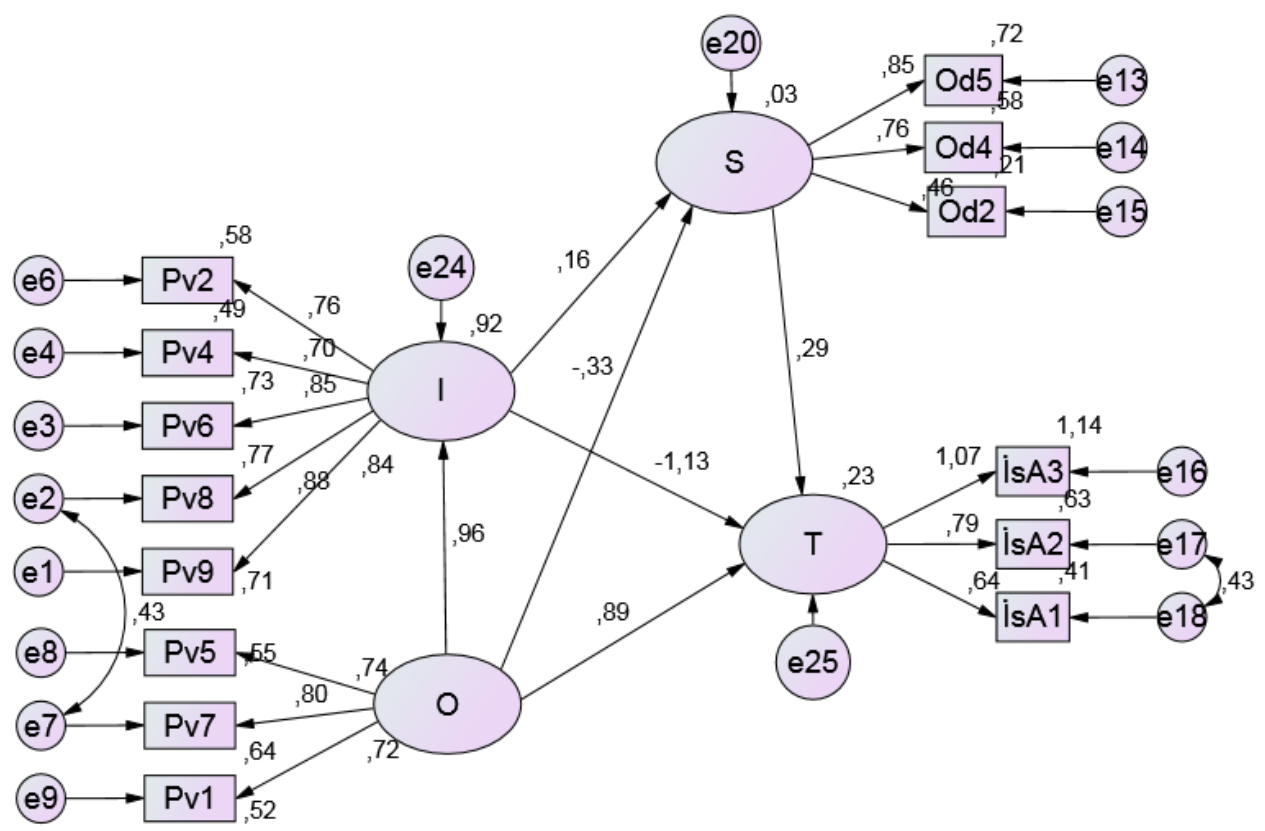

Figure 4. Structural equation model of Research Model

The results of the multiple regression analysis are within the acceptance limits. According to the model in Table 3, Intention to quit (T) variable; Organizational Support (S) (.244; p <0.05) and Internally Influenced Personal Values (I) $(-1.858 ; \mathrm{p}<0.05)$ variable. On the other hand, there was no effect between external values (O) and intention to quit (T). There is an inverse, positive and positive effect between the intention of quitting and personal values with internal factors such as happiness, personal development, pleasure in life, self-esteem and sense of success. On the other hand, there was no effect between external values $(\mathrm{O})$ and intention to quit (T). There is an inverse, positive and positive effect between the intention of quitting and personal values with internal factors such as happiness, personal development, pleasure in life, self-esteem and sense of success.

Table 3. Regresssion and Determination of Research Model

\begin{tabular}{|c|c|c|c|c|c|c|}
\hline & \multicolumn{6}{|c|}{ Standart regresyon katsayıları } \\
\hline $\mathrm{O}$ & $\rightarrow$ & I & 1.082 & .960 & .199 & $0 * * *$ \\
\hline $\mathrm{O}$ & $\rightarrow$ & $\mathrm{S}$ & -.722 & -.331 & .560 & 576 \\
\hline $\mathrm{I}$ & $\rightarrow$ & $\mathrm{S}$ & 6 & .158 & .524 & .786 \\
\hline $\mathrm{I}$ & $\rightarrow$ & $\mathrm{T}$ & .858 & -1.129 & .245 & $46^{*}$ \\
\hline $\mathrm{S}$ & $\rightarrow$ & $\mathrm{T}$ & 44 & .287 & .470 & $002 *$ \\
\hline $\mathrm{O}$ & $\rightarrow$ & $\mathrm{T}$ & 644 & .886 & .439 & .150 \\
\hline $\mathrm{O}$ & $\rightarrow$ & $\mathrm{I}$ & 1.082 & .960 & .199 & $0 * * *$ \\
\hline \multicolumn{4}{|c|}{ Yapısal Eşitlikler } & \multicolumn{3}{|l|}{$\mathbf{R 2}$} \\
\hline \multicolumn{4}{|c|}{$\mathrm{T}=(.244 * \mathrm{~S})+(-1.858) * \mathrm{I}$} & \multicolumn{3}{|l|}{$\% 2.3$} \\
\hline \multicolumn{7}{|c|}{$\begin{array}{l}* * * p<0.001 * * p<0.01 * p<0.05, \\
\text { O: External Personel Traites S:Organization Support } \\
\text { T: Turnover Intention, I: Internal Personel Traits }\end{array}$} \\
\hline
\end{tabular}

At the end of the research, there is a negative effect between organizational intention and happiness, personal development, enjoyment of life, self-esteem and self-esteem, which are listed as self-esteem. In this context, it is determined that individuals who give importance to development, enjoy life, are energetic and have high self-esteem will have a lower intention to quit. It was determined that individuals with these personal 
values had higher perceptions of organizational value. For this reason, companies should consider the personal values of their employees as an important criterion in determining the support practices they diversify in order to meet the expectations of their employees. I $\mathrm{n}$ this framework, the employment of competent individuals in the enterprise for the competitive advantage should be taken into consideration and ensuring the continuity of employment should be considered within this framework. Since personal values will affect the attitudes and behaviors of individuals in the enterprise, organizational support determined on an individual basis will increase the employee's sense of importance and value. People with high internal values who think that they are valued will continue to work in their enterprises instead of using these opportunities even if they have alternative job opportunities. The low intention of employees to leave the job, the trust-based relationship between the organization will increase the meeting of mutual expectations, will reduce the costs of leaving the business. In order to increase the contribution of this study to the literature, the limits of the study should be increased and the study should be enriched with qualitative data.

Keywords: Turnover Intention, Personal Values, Structural Eqoation Modeling, Perceived Organizational Support, Confirmatory Factor Analysis

Öz: Algılanan örgütsel destek, çalışanın işletmeye karşı olumlu tutum sergilemesinde etkilidir. Çalışanların algılanan örgütsel destek seviyelerinin yüksek olması üretkenlik karşıtı davranış ve tutumları azaltmaktadır. Kişisel değerler, bireylerin sosyal ve iş yaşamlarında geliştirecekleri tutumlar için bir çerçeve oluşturmaktadır. Üretkenlik karşıtı bir davranış olan işten ayrılma niyeti, işletmelere yüksek personel maliyetleri getirmektedir. Sağlık personeli çalışanlarının, işgücü piyasasında yüksek nitelikli ve eğitimli kesimi oluşturmaları, işe alım sonrası oryantasyon ve eğitim maliyetlerinin yüksek olması nedeniyle işten ayrılma kararını azaltacak örgütsel uygulamaların belirlenmesi önemlidir. İşten ayrılma kararında sadece çevresel faktörler değil, kişisel faktörlerin de etkili olması nedeniyle örgütsel faktörlerin dışında kişiliğin de işten ayrılma niyeti üzerindeki etkisini belirlemek gerekmektedir. Bu bağlamda, nicel araştırma yöntemi kullanılarak çalışmada işten ayrılma niyetinin çalışanlarda düşük seviyede olması için örgütsel destek ve kişisel değerlerin ilişkisi ele alınmıştır. Araştırmaya veri sağlamak için anket yoluyla sağlık sektöründe çalışan 363 kişiye ulaşılmıştır. Araştırma sonucunda İşten Ayrrlma Niyeti, Örgütsel Destek (S) $(.244 ; \mathrm{p}<0.05)$ ve İçsel Kişisel Değerlerden $(-1.858$; $\mathrm{p}<0.05)$ etkilenmekte olduğu belirlenmiştir. Diğer yandan dışsal kişisel değerler ile işten ayrilma niyeti arasında herhangi bir etki bulunamamıştır. İșten ayrılma niyeti ile mutluluk, kişisel gelişim, hayattan zevk alma, kendine saygı ve başarı duygusu gibi içsel etkenli kişisel değerler arasında ters yönlü ilişki olduğu belirlenmiş̧tir. İșten ayrılma niyeti ile örgütsel destek arasında negatif yönlü bir etki olduğu sonucuna varılmıştır. Araş̧ırma sonunda özellikle sağlık sektöründe çalışan yönetici ve İnsan Kaynakları uzmanlarına işten ayrılma niyetlerini düşürmek adına çalışanlara örgütsel destek sağlanması gerektiği önerilmiştir. Çalışanın ihtiyaç duyacağı destek kişiye özel olacağından, yöneticilerin çalışanlarının ihtiyaçlarını doğru belirlemesi önerilen yöntemlerden biridir. Çalışan ihtiyaçlarının belirlenmesinde kişisel değerlerin belirleyici rolü de yöneticilere doğru veri sağlamada önemli bir ipucu olacaktır. Araştırma sonuçlarına dayanarak çalışanlara sağlanacak desteğin içsel değerleri olan bireylerin işe devam etme isteklerini artıracağ görülmektedir. Bu nedenle örgütlerin kişisel değerli yüksek olan bireylere işlerini daha iyi yapmalarını, işe alan katkılarını artırmalarını sağlayacak destek mekanizmaları geliştirmeleri gerektiği belirlenmiş̧ir..

Anahtar Kelimeler: Algılanan Örgütsel Destek, İşten Ayrılma Niyeti, Kişisel Değerler, Yapısal Eşitlik Modeli, Doğrulayıcı Faktör Analizi

\section{Giriş}

Organizasyonların yapı ve işleyişinde kişisel değerlerin, bireylerin organizasyona yönelik geliştirdikleri tutum ve davranışlarda etkili olduğu görülmektedir. İnsan gücünün, örgütler için rekabet avantajı sağlayacak olması nedeniyle yetkin olan çalışanın elde tutulması, turn-over oranının düşük olması örgütler için arzulanan bir durum haline gelmektedir. Çalışanın işletmeye karşı olumlu tutum sergilemesinde ve performansını istenilen düzeyde tutmasında karşılıklılık ilkesi gereği örgütten destek alabilmesi zorunluluk olarak görülmektedir. Bu nedenle, çalışmada istenilmeyen bir sonuç olan işten ayrılma niyetinin çalışanlarda düşük seviyede olması için örgütsel destek ile ilişkisi, kişisel değerler kavramı bağlamında ele alınmıştır. Çalışmada kavramsal çerçeve başlığında 
araştırma değişkenleri olarak örgütsel destek, işten ayrılma niyeti ve kişisel değerlerden bahsedilmiştir. Araştırmanın ampirik analiz kısmında 368 sağlı sektörü çalışanının katılımıyla elde edilen veriler, istatistiki analizler ile incelenmiş ve değişkenler arasındaki ilişkiler belirlenmiştir.

\section{Kavramsal Çerçeve}

Bu başlık altında aaştırma değişkenlerine ilişkin kavramsal çerçeve çizilererek araştırmanın analizlerini yorumlamak için alt yapı oluşturulmuştur.

\subsection{Algılanan Örgütsel Destek}

Kaynağı çok çeşitli olmakla birlikte örgüt desteği çalışanlar için birçok tutum ve davranışın öncülüdür. Örgütsel destek kavramı, ilk kez 1986 yılında Esisenberger v.d. tarafından yapılan çalışmalarla algılanan örgütsel destek (perceived organizational support) olarak kavramsallaşmış ve yönetim-organizasyon literatüründe yerini almıştır. Algılanan örgütsel desteği, çalışanların mutluluğuna ve refahına örgütlerin ne derece önem verdiği ve verilen bu önemin ne düzeyde birey tarafından hissedildiği olarak tanımlanmaktadır (Eisenberger vd. 1986: 500-501). Algılanan örgütsel destek kavramı, çalışanın örgütün sunacağı kolaylaştırıcı ve destekleyici faaliyetlerin ne derece hissedildiği olarak belirtilmektedir (Matthews vd., 2009: 78-90).

Algılanan örgütsel destek kavramın temelinde, Sosyal Değişim Teorisi(Social Exchange Theory) ve Psikolojik Sözleşme Teorisi (Pyscholojical Contract Theory) yer almaktadır. Sosyal alış veriş teorisine göre birey ve organizasyon arasında karşılıklılık ilkesi gereği sosyal maliyetlerin de beklentiler doğurduğu belirtilmektedir. Bu nedenle örgüte çalışanın yapacağı katkının maddi ve maddi olmayan şekilde karşılık görüyor olmasının, bireyin örgüte olan katkısının artmasında önemli bir rol oynayacağı belirlenmiştir (Parameswaran, v.d., 2013: 7). Biçimsel ve yazılı olmayan sözleşmeler olarak tanımlanan psikolojik sözleşmelere göre, örgüt ve çalışan arasında şartları ve içeriği çoğu zaman dile getirilmeyen ama beklentileri içeren, somut ve ekonomik zorunlulukların karşılıklılığını içeren dönüşümsel, sosyo-duygusal zorunlulukları içeren ilişkisel boyutları ile psikolojik sözleşme tipi bulunmaktadır (Rousseau ve Parks, 1992: 1-43).

Algılanan örgütsel destek çalışmalarında, destek türleri duygusal (emotional), araçsal (instrumental), bilgisel (informational) ve değerlendirme (esteem), kariyer (career), maddi destek (material) gibi başlıklar altında ele alınmaktadır (Kraimer ve Wayne, 2004: 209: Rooney, Benjamin H. Gottlieb, 2007: 187: Bhanthumnavin, 2003: 155-166: Thompson, Beauvais, Lyness, 1999: 393: Kraimer, Wayne, 2004: 217-218, Aydın Göktepe, 2017: 58). Duygusal destek, bireylere sayg1 gösterme, değer verme, çatışma ve stres yönetiminde destek verme gibi faaliyetleri içermektedir. Araçsal destek, maddi mallar ve hizmetlerin temin edilmesini kapsamaktadır (Rooney, Benjamin $\mathrm{H}$. Gottlieb, 2007: 187). Bilgisel destek (informational support), çalışanların performansını yükseltmek adına yapılan ödüllendirme, cezalandırma, geribildirimde bulunma ve gereken bilgi ve beceriyi kazandırma faaliyetleri olarak sıralanmıştır (Bhanthumnavin, 2003: 155-166). Araçsal desteğin maddi desteği (material support) de içine aldığını belirten kaynaklarda, bireylerin amaçlarına ulaşmalarını sağlayacak somut kaynakların (malzeme- alet gibi), zamanın, parasal kaynağın ve insan kaynağının temin edilmesi araçsal destek olarak belirtilmiştir. (Thompson, Beauvais, Lyness, 1999: 393). Değerlendirme desteği, performans yönetimi sürecinde çalışana kendi performans değerlemesi hakkında geribildirimde bulunulmasını ifade etmektedir. Kariyer, bireylerin basamaksal olarak, dikey ve yatay olarak ilerleme firsatları yaşamasını sağlayan istihdam biçimi (Arthur ve Lawrence, 1984: 1) ve bireyin iş yaşamı boyunca edinmiş olduğu iş rollerinin toplamı (Granrose, 1995: 5) olarak tanımlanmaktadır. Algılanan örgütsel desteğin kariyer desteği (career support) boyutu, organizasyonun çalışanın kariyer ihtiyaçları ile ilgilenmesi, bu konuda uygulamalar ve politikalar geliştirmesi olarak tanımlanmıştır (Kraimer, Wayne, 2004: 217-218).

Organizasyonların çalışanlarının sadakatine ve bağlılıklarına da ihtiyaç duyuyor olmaları, organizasyonun olumlu iş çıktılarını artırma isteği nedeniyle farklı örgütsel davranış öncüllerine 
eğilmelerini zorunluluk haline getirmektedir. $\mathrm{Bu}$ kavramlardan biri olarak örgütsel destek, kendilerine gösterilen değer, takdir ve refahlarının düşünülmesi karşılığında, bireyler organizasyonların beklentilerini karşılayacak şekilde performanslarını artırma, iş arama ve devamsızlık oranlarını azaltma şeklinde cevap vermesini sğlamaktadır (Rhoades and Eisenberger, 2002: 698).

Örgütsel desteğin algılanmasında bireysel özellikler de etkili olmaktadır. Kişilik yapısı, değerler, yaş, eğitim, cinsiyet ve çalışma yılı gibi demografik özellikler de örgütsel destek algısında etkili olmaktadır. Örneğin; çalışma yılı daha uzun olan çalışanların çok daha fazla ve farklı açılardan destek gördüğü belirtilmiştir (Rhoades, Eisenberger, 2002: 701).

\section{2. İșten Ayrılma Eğilimi}

Örgütsel amaçlara ulaşmada örgüte katkısı beklenildiği gibi ya da beklentinin üstünde olan çalışanların, işletmeden ayrılma isteği rekabet avantajı sağlayan insan kaynağının kaybı olarak işletmede olumsuz iş çıktılarına neden olmaktadır. Bireylerin işten ayrılma eğilimi göstermeleri, ait oldukları örgütün sektördeki başarısına, bireyin kendi başarılarının yeterlilik düzeyine ve gelecekte yer alabileceği olası pozisyonlarına bağlıdır (Hardy, 1987). İșten ayrılma eğilimi kavram olarak, kişilerin yer aldıkları örgütten ayrılma fikrine karşı sergilediği tutumu kapsamaktadır, yani bireyin işten ayrılmasının fiziksel olarak gerçekleşmediği fakat psikolojik olarak bu fikri davranışa dönüştürmeye hazırlıklı olduğu anlamını taşımaktadır (Kassing vd., 2012: 241).

İşten ayrılma eğiliminin birçok örgütsel davranış değişkeni ile ilişkisi bulunmaktadır; eğitim düzeyi ile işten ayrılma eğilimi pozitif, yaş ve kıdem ile negatif yönlü ilişki olduğu, aşırı iş yükü, düşük ücret, örgütsel maddi desteğin olmayışı, terfi imkanının olmaması ile işten ayrılma eğilimin negatif yönlü ilişkili (Conklin ve Desselle, 2007: 3), ücret memnuniyeti ile işten ayrılma eğiliminin negatif yönlü ilişkili (Tekleab vd., 2005: 904), algılanan yönetici desteği ile işten ayrılma eğiliminin pozitif yönlü ilişkili olduğu(Kim vd., 2012: 1250, Kang vd., 2015: 69) belirtilmiştir. Yapılan bu çalışmalar işten ayrılma eğiliminin örgütler için öneminin altını bir kez daha çizmekte ve bu çalışmanın araştırma değişkeni olarak belirlenmesinde neden oluşturmaktadır.

İşten ayrılma eğilimi birçok örgütsel davranış ve tutumla ilişkili olarak ele alınmakla birlikte, yazında işten ayrılma eğilimi en çok iş doyumu ile ilişkisi ele alınmaktadır. İş doyumu ve işten ayrılma eğilimi ilişkisine dayanan Mobley v.d.'nin (1979) geliştirdiği modele göre, iş doyumu yüksek olduğunda birey işten ayrılma düşüncesine sahip olmayacak, iş doyumu düşük olduğunda ise işten ayrılma sonrası ne durumda olacağını düşünerek, bu düşüncenin rasyonel olup olmadığını filtreleyerek karar verecektir (Mobley, vd., 1979). Çalışanlar yapmış oldukları katkılara örgüt tarafından eşit oranda bir karşılık gördüklerini düşünmediklerinde iş doyumları azaltacak ve performanslarını düşürme veya işi bırakma eğilimi göstermeye başlayacaklardır. (Mobley vd., 1979: 493-522)

Bireylerin örgüt dışında daha avantajlı fırsatlar elde ettiklerinde işten ayrılmama eğilimi sergileyeceği durumların neler olduğunu belirlemeye yönelik çalışmalarda, bireylerin işten ayrılma eğilimi göstermeme nedenlerini, çalışanın organizasyon ile gurur duyması, üst yöneticisi ile uyumlu çalışıyor olması, adil ücretlendirme politikasının olması, itibarlı meslektaşlarla çalışma olanağı, meslektaş uyum ve desteği, yapılan işi anlamlı bulma olarak belirlenmiştir (Waldroop ve Butler, 2011).

\subsection{Değerler}

Değer kavramı, ahlak kuralları ile ilişkilendirilerek irdelenen ve insan davranışını açıklamakta kullanılan önemli bir araçtır. Değerler, bireyin ruhsal bütünlüğünü sağlaması ve sosyal kabul görme ihtiyacı ile ilişkilidir. Değerler aynı zamanda tutum ve davranışların önceden tahmin edilmesini de sağlamaktadır. Bu bağlamda sosyal bilimcilerin çalışan davranış ve tutumlarının nedenlerini belirlemek için birey ve grup düzeyinde değer kavramını araştırma konusu olarak ele 
Esra Aydın Göktepe - Pervin Tunç - Osman Yıldırım - Hakan Tetik

aldıkları görülmektedir. (Kâğıtçıbaşı ve Kuşdil, 2000: 60, Kuçuradi, 2013: 5). Değerler bir bireyin özgün tutumlarının şekillenmesinde etkili olan, bireyin tercihlerine, kararlarına ve davranışlarına yol gösteren kanaatler, bireylerin alternatif davranış biçimleri arasında seçim yapmasını sağlayan normatif standartlardır (Becker ve McClintock, 1967). Değerler, genetik yapılar ile şekillenir ve her birey üyesi olduğu toplumdan öğrenerek değerlerini içselleştirir. (Keller,1992). Değerler, bireyin davranışlarına, düşüncelerine, yaşamına rehberlik yapan bir güç olarak görülmektedir (Gutman 1982:60). Yazında, değerleri belirlemeye yönelik çok sayıda çalışma bulunmaktadır. Bu çalışmalara göre değerler; güvenlik, saygınlık arama, toplumsal konumunu koruma, hayattan zevk alma, başarılı olma, toplum tarafindan aranan istenen birisi olma (Kahle, 1985), gerçeği ve adaleti arama, kendini koruma, kendine sayg1 gösterme, kendini disipline etme, alçakgönüllü olma, başkalarına karş1 saygıl1, hoşgörülü ve bağışlayıcı olma, çevreyi ve canlıları koruma (Kinnier, Kernes ve Dautheribes, 2000) olarak sıralamışlardır. Değerler işletmelerin birçok süreci için belirleyici bilgi sağlayabilmektedir. Örneğin kriz dönemlerinde ivedilikle ve soğukkanlı olarak karar verilmesi gerekmektedir (Küçükaltan ve Ergin, 2009, s.216) Bu dönemlerde risk alan ve cesaret değeri yüksek olan kişilerin belirlenmesi ve yönetsel pozisyonlara getirilmesi, çalışanın değerlerinin doğru belirlenmesi ile mümkün olacaktır.

Yazında yaygın olarak kullanılan değerler ölçekleri; Rokeach Degerler Sistemi (RVS) Ölçeği, Değerler ve Yaşam Biçimi Sistemi (VALS) Ölçeği ve Değerler Listesi (LOV) Ölçeğidir. Rokeach (1972), belirlemiş olduğu on sekiz değeri araçsal değerler ve amaçsal değerler başlığ1 altında toplamıştır. Araçsal değerler amaçsal değerlere ulaşmak için tercih edilen davranış biçimini ifade eder. Araçsal değerler, açık fikirlilik, cesaret, nezaket, dürüstlük, hırslı ve cesur olma, yeterlilik, kibarlık gibi değerlerden oluşur. Amaçsal değerler, kişinin hayatında olmak istediği, ulaşmak istediği durumu ve ortamı ifade etmektedir. Rahat bir yaşam, özgürlük, aile güvenliği gibi değişkenlerden oluşmaktadır. (Pitts, Canty, Tsalikis, 1985:268; Beatty, Kahle, Homer, Misra, 1985:183; Prakash, Munson, 1985:282; Odabaş1, 2002:213-214). Değerler ve Yaşam Biçimi Sistemi (VALS), Maslow'un ihtiyaçlar hiyerarşisi teorisine dayandırılarak geliştirilmiştir ve bireyin psikolojik özelliklerine ve yaşam tarzlarına odaklanmıştır. (Hayer Macilnnis, 1997:433; Solomon, 1996:588). $\mathrm{Bu}$ sistemde kişiler, içe ve dışa dönük olmalarına göre iki grup altında toplanmıştır.

Bir diğer değerler ölçeği Değerler Listesi (LOV) ise, 1983 yılında Kahle tarafindan geliştirilmiştir. Kahle (1983), değer ölçeğini geliştirilirken Maslow'un ve Rokeach'ın çalışmalarını kullanmıştır (Beatty, Kahle, Homer, Misra, 1985:186). Kahle'ye göre kişilerin değerleri sergiledikleri rollere göre farklılık göstermektedir. Bireylerin değerleri toplumda karş1lıklı etkileşim ve tecrübelerinin sonucunda gelişmektedir (Shao, 2002:24-25). LOV ölçeğinde yer alan sekiz temel değer, ait olma, kendine saygı duyma, güvende olma, hayattan zevk alma, sıcak ilişkiler kurma, sayg1 görme ve gelişim sağlama olarak belirtilmiştir. Ait olma değeri; bireyin içinde bulunduğu sosyal çevreden ihtiyaç duyduğu önemi görmesi, kendine sayg1 duyma değeri; bireyin yaptığı işten gurur duymasını ve kendini güvende hissetmesini, yaptıkları ile gurur duymasını, güvende olma değeri; yaşadığı problemlerde destek göreceği inancına sahip olmayı, hayattan zevk alma değeri; hayatından keyif alabiliyor olmasını, sıcak ilişkiler kurma değeri; üyesi olduğu grup tarafından ilgi görmesini, saygı görme değeri; toplum tarafindan saygıdeğer bulunma ve onaylanmayı, başarılı olma değeri; amaçlarına ulaşabilmeyi, kişisel gelişim sağlama değeri; bireyin yeteneklerinin farkında olmasını ve onları etkin kullanabilmesini kapsamaktadır (Beatty, Kahle, Homer, Misra, 1985:186). Bu çalışmada, değerleri ölçmek için Değerler Listesi Ölçeği kullanılmıştır.

\section{Metodoloji}

Bu başlık altında çalışmanın örneklemi, kullanılan ölçekler, analizler ve analizlerin yorumlarına yer verilmiştir.

Turkish Studies - Economy, 15(1) 


\section{2. Çalışmanın Örneklemi}

Çalışmanın veri toplama aracı anket olarak belirlemiş olup, araştırmanın gerçekleştirileceği sektör sağlık sektörü olarak sınırlandırılmıştır. Çalışmaya sağlık sektöründe çalışan 368 gönüllü katılımcı dahil olmuştur. Katılımcıların 52.3\%'i kadınlardan oluşmaktadır. 47.1\%'si yaşları 25-29 arasında olan bireylerden, 86.8\%'si ise üniversite mezunlarından oluşmaktadır. Ayrıca iş deneyimleri 1 yıl ile 5 yıl arasında olanların oranı $47.1 \%$ olarak belirlenmiştir.

\subsection{Araştırmada Kullanılan Ölçekler}

Algılanan Örgütsel Destek Ölçeği; Eisenberger vd.'nin (1986) yılında gelişirmiş olduğu 36 maddeden oluşan ve 2002 y1lında revize ederek 16 maddeli ölçeğin, Tokgöz'ün (2002) çalışmasında verilen kısa versiyonlu 6 maddeden oluşan Algılanan Örgütsel Destek Ölçeği (AÖDÖ) kullanılmıştır. Ölçeğin her bir soru maddesine verilen cevaplar 5'li likert ölçeği ile alınmıştır (1=Kesinlikle katılmiyorum, 5=Kesinlikle kat1lıyorum).

İşten Ayrılma Niyeti Ölçeği; Çalışmada Mobley, Horner ve Hollingsworth (1978; 410) tarafından geliştirilen 3 maddeli İşten Ayrılma Niyeti Ölçeği (Turnover İntention) kullanılmıştır. Ölçeğin her bir soru maddesine ilişkin cevaplar 5'li likert ölçeği ile alınmıştır (1=Kesinlikle katılmiyorum, 5=Kesinlikle kat1lıyorum).

Kişisel Değer Ölçeği; Kahle (1983) yılında geliştirmiş olduğu 8 temel değeri ölçen, 8 maddeli LOV ölçeği kullanılmıştır.

\section{4. Çalışmanın Analizleri}

Çalışmaya katılanların anket yanıtları SPSS for Windows 22.00 ve AMOS 22.0 programı kullanılarak analiz edilmiş, ardından literatür ışığında düzenlenip yorumlanmıştır. Araştırmada kullanılan ölçeklerin doğrulayıcı faktör analizleri AMOS programında yapılmıştır.

\subsubsection{Geçerlilik ve Güvenilirlik Analizleri}

Tutumları ölçmek için kullanılan ölçeklerin, öncelikli olarak ölçmek istenen değişkeni ölçüp ölçmediğini belirlemek için güvenilirlik ve iç tutarlılık analizi değerlendirilmelidir. Bu araştırmada, güvenilirlik analizi için sorular arası korelasyona bağlı uyum değeri olan Cronbach's Alpha modeli kullanılmıştır. Tablo 1'de araştırma ölçeklerinin güvenilirlik ve iç tutarlılık değerleri gösterilmiştir.

Tablo 1: Kullanılan ölçeklerin güvenilirlik değerleri

\begin{tabular}{lcc}
\hline \multicolumn{1}{c}{ Ölçek Adı } & Madde Sayısı & Cronbach's Alpha \\
Örgütsel Destek (S) & 6 & .737 \\
İşten Ayrılma Niyeti (T) & 3 & .879 \\
Kişisel Değerler (PV) & 8 & .916 \\
İçsel Değerler (I) & 5 & .884 \\
Dişsal Değerler (D) & 3 & .775 \\
\hline
\end{tabular}

Tablo 1'de gösterilen araştırma kapsamında katılımcılara uygulanan ölçeklerden "Örgütsel Destek" (.737) değeri ile oldukça güvenilir, "İşten Ayrılma Niyeti” ölçeği ile "Kişisel Değerler" ölçeği sırasıyla (.879) ile (.916) değerleri ile yüksek güvenilir seviyesinde yer almaktadır. "Örgütsel Destek" ile "İșten Ayrılma Niyeti" 3'er maddeden oluşan tek boyutlu faktörlerdir. "Kişisel Değerler" ölçeği ise 8 madde ve 2 boyuttan oluşmaktadır. İlk boyut "içsel Değerler" 5 maddeden oluşmuştur ve Cronbach's Alpha değeri(.884) ile oldukça güvenilir, "Dışsal Değerler" 3 maddeden oluşup Cronbach's Alpha değeri(.775) ile oldukça güvenilir düzeyde bulunmaktadır. 


\subsubsection{Doğrulayıcı Faktör Analizi}

Doğrulayıcı Faktör Analizi (DFA) ile her ölçek için ayrı ayrı ölçüm modellerinin anlamlı olup olmadığı AMOS 22.0 paket programı ile araştırılmıştır. Ölçüm modellerinin kabul edilebilir olduğu görülmüştür. Sonrasında tam modelin uygunluğunun açıklanması, iyi uyum ölçütleri yardımıyla yapılmıştır. Örnek büyüklüğü arttıkça, özellikle 200'den büyük örneklerde Ki-Kare (x2) değeri de yüksek çıkmakta ve bununla birlikte Ki-Kare (x2) testinin istatistiksel anlamlılık düzeyi düşük çıkmaktadır (Bollen, 1989: 256; Fornell ve Larcker, 1981: 40)

Araştırma için kullanılan ölçeklerin doğrulayıcı faktör analizi değerlendirmesinde ve genel test edilen modellerin uygun olup olmadığına düzeltilmiş Ki- Kare(x2) değeri (Ki-Kare değeri/Serbestlik derecesi) ile diğer uyum iyiliği indeksleri ve standartlaştırılmış artık kovaryans matrisinde yer alan değerlerin incelenmesi sonucunda karar verilmiştir (Meydan, 2011, s.132)

Tablo 2'de verilmiş olan doğrulayıcı faktör analizi sonucunda elde edilen model test değerlerinden $\mathrm{x} 2 / \mathrm{df}$ değeri (1.812) bulunduğundan DFA' nın anlamlı olduğu anlaşılmaktadır. Modelin uyum indeks değerleri ise GFI(.997),CFI (.996), SRMR (.0166), RMSEA (.047 ) ile kabul edilebilir sınırlar içindedir ve bu nedenle Örgütsel Destek(S) ölçeğinin Doğrulayıcı Faktör analizinin geçerli olduğu sonucuna ulaşılmıştır.

Tablo 2: Doğrulayıcı Faktör Analizinde Kullanılan Uyum İyiliği İndeksleri ve Uyum Değerleri

\begin{tabular}{ccc}
\hline Indeksler & İyi Uyum & Kabul Edilebilir Uyum \\
\hline$\chi 2 / \mathrm{df}$ & $0 \leq \chi 2 / \mathrm{df} \leq 2$ & $2<\chi 2 / \mathrm{df} \leq 5$ \\
GFI & $\geq 0,90$ & $0,85-0,89$ \\
$\mathrm{CFI}$ & $\geq 0,97$ & $, \geq 0,95$ \\
SRMR & $\leq 0,05$ &, $06 \leq \mathrm{SRMR} \leq, 08$ \\
RMSEA & $\leq 0,05$ &, $06 \leq \mathrm{RMSEA} \leq, 08$ \\
\hline
\end{tabular}

Örgütsel Destek (S) için Doğrulayıcı Faktör Analizi. 6 maddeden oluşan Örgütsel Destek ölçeğinden 3 madde madde faktör yüklerinin (0.50) değerinden düşük olması dolayısıyla analizden çıkarılmıştır. Analizden çıkarılan maddeler "Çalıştığım kurumda bana çok az ilgi gösterilir." ile "İ̧̧imi olabilecek en üst düzeyde yapsam bile, çalıştığım kurumda bu fark edilmez. " şeklinde olan maddelerdir. Şekil 1'de Örgütsel destek ölçeğinin doğrulayıcı faktör analizi sonuçları verilmiştir. Kalan 3 madde ile yapılan DFA sonucunda madde faktör ağırlık değerleri $(0.54 ; 0.81)$ aralığında yer almaktadır.

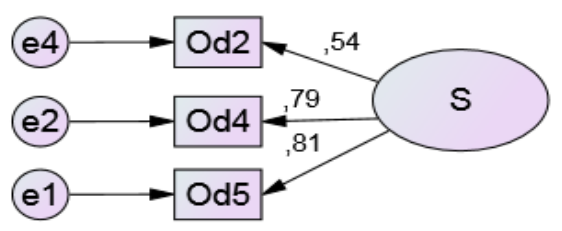

Şekil 1. Örgütsel Destek(S) ölçeği için DFA 


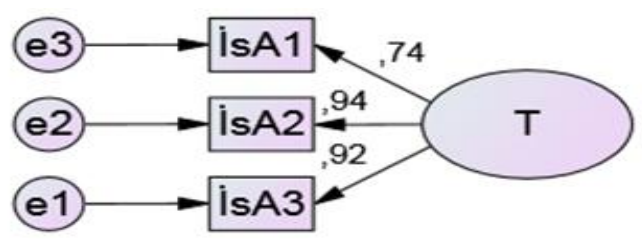

Şekil 2. İşten Ayrılma Niyeti (T) ölçeği için DFA

İşten Ayrılma Niyeti (T) Ölçeği için Doğrulayıcı Faktör Analizi. 3 maddeli İşten Ayrılma Niyeti (T) ölçeği tek boyutlu bir ölçektir. Şekil 2'de İşten ayrılma niyeti ölçeğinin doğrulayıcı faktör analizi sonuçları verilmiştir. Maddelerin faktör ağırlıkları $(0.74 ; 0.94)$ aralığındadır.

Doğrulayıcı faktör analizi sonucunda elde edilen model test değerlerinden $\mathrm{x} 2 / \mathrm{df}$ değeri (3.393) bulunduğundan DFA' nın anlamlı olduğu anlaşılmaktadır. Modelin uyum indeks değerleri ise GFI(.991),CFI (.981), SRMR (.0149), RMSEA (.080 ) ile kabul edilebilir sınırlar içindedir ve bu nedenle İşten Ayrılma Niyeti $(\mathrm{T})$ ölçeği Doğrulayıcı Faktör analizinin geçerli olduğu sonucuna ulaşılmıştır.

Kişisel Değerler (PV) Ölçeği için Doğrulayıcı Faktör Analizi. 8 maddeden oluşan Kişisel Değerler (PV) ölçeği 2 alt boyuttan oluşmaktadır. İlk boyut 5, diğer boyut ise 3 madde ile açıklanmaktadır. Şekil 3’te kişisel değerler ölçeğinin doğrulayıcı faktör analizi sonuçları verilmiştir. Ölçekteki maddelerin faktör ağırlıkları $(0.69 ; 0.84)$ aralığındadır.

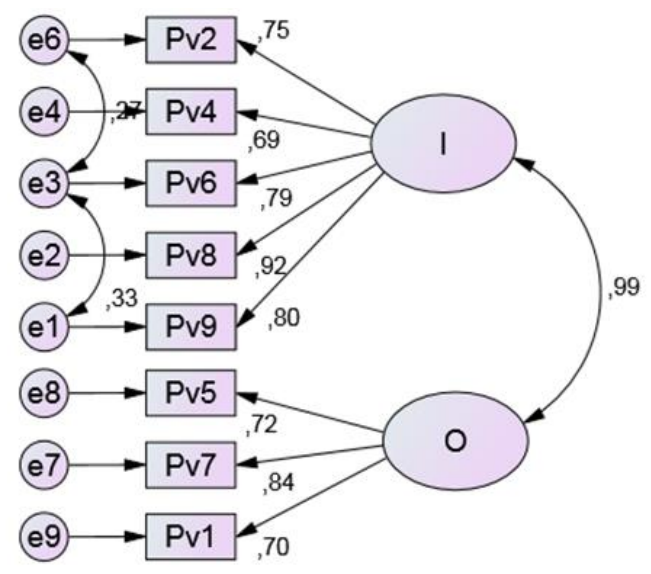

Şekil 3. Kişisel Değerler (PV) Ölçeği için DFA

Doğrulayıcı faktör analizi sonucunda elde edilen model test değerlerinden $\mathrm{x} 2 / \mathrm{df}$ değeri (2.755) bulunduğundan DFA' nın anlamlı olduğu anlaşılmaktadır. Modelin uyum indeks değerleri ise GFI(.946),CFI (.973), SRMR (.0309), RMSEA (.084) ile kabul edilebilir sınırlar içindedir ve bu nedenle Kişisel Değerler (PV) Ölçeği için uygulanan Doğrulayıc1 Faktör analizinin geçerli olduğu sonucuna ulaşılmıştır.

\subsection{3. Ölçeklere Ait Yapısal Eşitlik Modellemesi ile Yol Analizi}

Hipotezlerle öngörülen etkileri araştırmak için AMOS 22.0 paket programı ile path diyagramı çizilmiş ve yapısal parametrelerin tahmininde En Çok Olabilirlik Yöntemi kullanılmıştır. Modelin Path diyagramı Şekil.4 'te verilmiştir. AMOS SEM programı analiz sonuçlarını 
standartlaştırılmış ve standardize edilmemiş katsayılar olarak ayrı ayrı vermektedir. $\mathrm{Bu}$ analiz çalışmasında anlaşılabilirlik açısından standartlaştırılmış katsayılar kullanılmıştır.

Yapısal eşitlik modellemesinde model uyumu için hesaplanan kikare değeri, örneklem hacminin büyüklüğünden ve değişken sayısından etkilenerek yanlış kararlar vermeye sebep olabileceğinden, bu değer yerine, (x2/ df) ölçütüne bakılarak karar verilir (Hair, et.al., 1998; Jöreskog and Sörbom, 1996; Schermelleh-Engel et.al 2003; Raykov and Marcoulides, 2006).

Yapısal eşitlik modeli sonuçları olarak x2/ df $(1.513)$ ve $(p<0,05)$ elde edilmiştir. Ayrıca yapısal eşitlik modeli iyi uyum indeks değerleri (RMSEA (0.051), GFI (0.930), CFI (0.979) ve SRMR (0.0459)) kabul edilebilir sınırlar içerisinde elde edilmiştir. Şekil 4'te ölçeklere ait yapısal eşitlik modellemesi sonucunda elde edilen yol analizi verilmiştir.

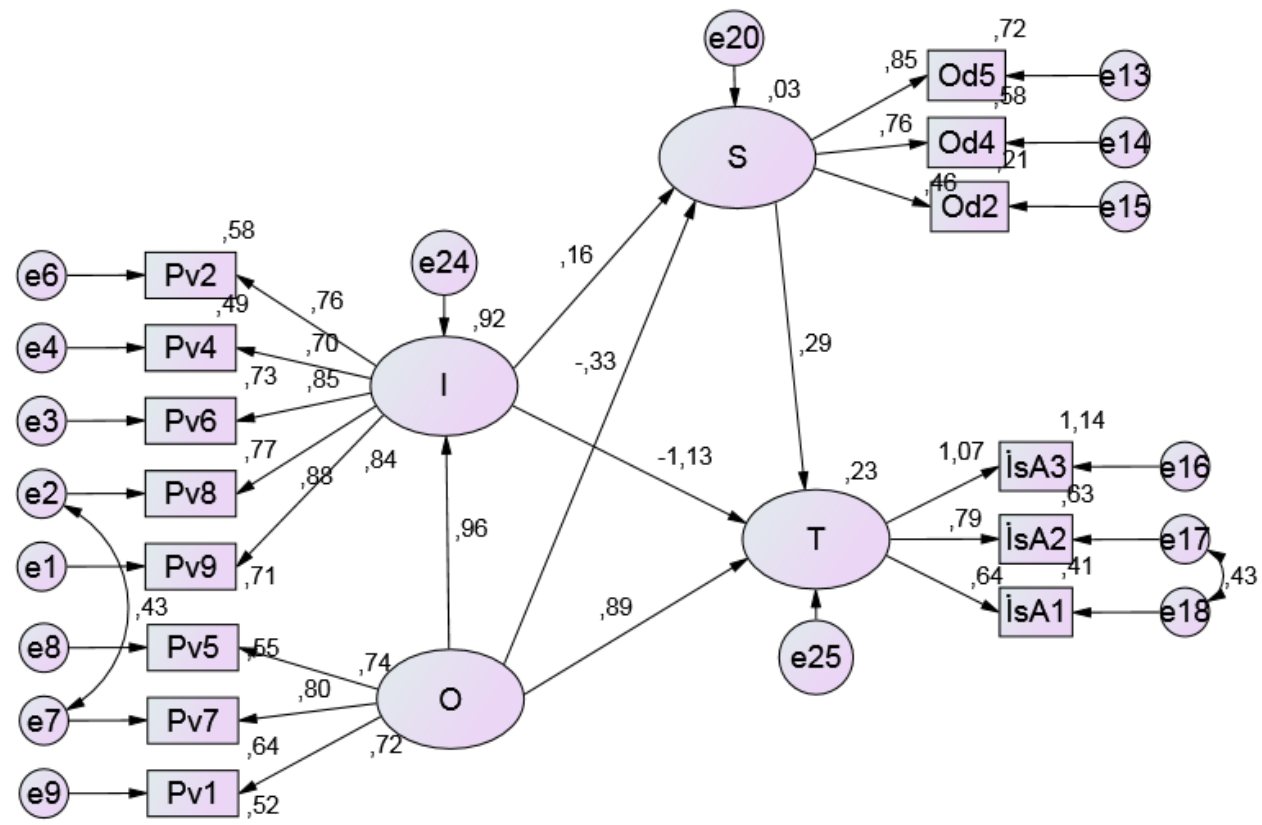

Şekil 4. Ölçeklere ait Yapısal Eşitlik Modeli

Şekil 4'te gösterilen modelden elde edilen regresyon ve determinasyon katsayıları Tablo 3'te gösterilmiştir.

Tablo 3: Modelden hesaplanan Regresyon ve determinasyon katsayıları

\begin{tabular}{|c|c|c|c|c|c|c|}
\hline & \multicolumn{6}{|c|}{ Standart regresyon katsayıları } \\
\hline $\mathrm{O}$ & $\rightarrow$ & $\mathrm{I}$ & 1.082 & .960 & .199 & $0 * * *$ \\
\hline $\mathrm{O}$ & $\rightarrow$ & $\mathrm{S}$ & -.722 & -.331 & .560 & 576 \\
\hline $\mathrm{I}$ & $\rightarrow$ & $\mathrm{S}$ & 6 & .158 & .524 & .786 \\
\hline I & $\rightarrow$ & $\mathrm{T}$ & .858 & -1.129 & .245 & $46^{*}$ \\
\hline $\mathrm{S}$ & $\rightarrow$ & $\mathrm{T}$ & 44 & .287 & .470 & $002 *$ \\
\hline $\mathrm{O}$ & $\rightarrow$ & $\mathrm{T}$ & 644 & .886 & .439 & .150 \\
\hline $\mathrm{O}$ & $\rightarrow$ & I & 1.082 & .960 & .199 & $0 * * *$ \\
\hline \multicolumn{4}{|c|}{ Yapısal Eşitlikler } & \multicolumn{3}{|l|}{$\mathbf{R 2}$} \\
\hline & & & & $\% 2.3$ & & \\
\hline \multicolumn{7}{|c|}{$\begin{array}{l}\text { O: Diş etkenli Kişisel Değerler, } \\
\text { S:Örgütsel Destek } \\
\text { T: İşten ayrılma niyeti, I: İçsel etkenli Kişisel Değerler }\end{array}$} \\
\hline
\end{tabular}


Elde edilen çoklu regresyon analizinin sonuçları kabul sınırları dahilindedir. Tablo 3'deki modele göre, İşten Ayrılma Niyeti(T) değişkeni; Örgütsel Destek(S)(.244; $\mathrm{p}<0.05)$ değişkeni ile İçsel etkenli Kişisel Değerler(I) (-1.858; $\mathrm{p}<0.05)$ değişkeninden etkilenmektedir. Diğer yandan dişsal değerlerler $(\mathrm{O})$ ile işten ayrılma niyeti(T) arasında herhangi bir etki bulunamamıştır. İșten ayrılma niyeti ile mutluluk, kişisel gelişim, hayattan zevk alma, kendine saygı ve başarı duygusu şeklinde sıralanan içsel etkenli kişisel değerler arasında ters yönlü, örgütte destek ile pozitif yönlü bir etki vardir.

\section{Sonuç ve Tartışma}

Araştırmanın sonunda işten ayrılma niyeti ile mutluluk, kişisel gelişim, hayattan zevk alma, kendine saygı ve başarı duygusu şeklinde sıralanan içsel etkenli kişisel değerler arasında ters yönlü, örgütsel destek ile negatif yönlü bir etki vardır. Bu bağlamda, örgütlerin kişisel değerleri gereği gelişime önem veren, hayattan zevk alan, enerjik olan, kendine saygısı yüksek olan bireylerin işten ayrılma niyetinin daha düşük olacağı belirlenmiştir. Bu araştırma bulgusu sağlık sektöründeki İnsan Kaynakları Yöneticilerin işe alım sürecinde uygulayacağı kişilik testlerinin sonuçlarını işe alım kararı sürecinde yorumlarken kullanabileceği bir çerçeve sunmaktadır. Sağlı sektörde çalışanlarının içsel değerleri yüksek bireylerden seçilmesi, işten ayrılmanın getirdiği maliyetleri azaltacaktır.

İçsel kişisel değerlere sahip bireylerin benzer şekilde örgütsel değer algılarının da daha yüksek olduğu belirlenmiştir. Bu nedenle işletmelerin çalışanlarının beklentilerini karşılamak için çeşitlendirdikleri destek uygulamalarını belirlerken çalışanlarının kişisel değerlerini önemli bir kriter olarak görmeleri gerekmektedir. İçsel değerleri yüksek bireylerin, çalıştıkları örgütlerin sunmuş olduğu maddi, duygusal, araçsal veya kariyer destek algılarının daha yüksek olduğu belirlenmiştir. $\mathrm{Bu}$ sonuca göre yönetimin sağlayacağı destek faaliyet ve uygulamaları ile içsel değerleri olan çalışanlar, dışsal değerleri olan çalışanlara kıyasla daha yüksek seviyede elde tutabileceklerdir.

Kişisel değerler bireylerin işletmedeki tutum ve davranışlarını etkileyeceğinden, bireysel bazda belirlenmiş örgütsel destek çalışanın kendisine verilen önem ve değeri hissetmesini artıracaktır. Kendisine değer verildiğini düşünen içsel değerleri yüksek kişiler, alternatif iş imkanlarına sahip olsalar bile bu firsatlan değerlendirmek yerine işletmelerinde çalışmaya devam edeceklerdir. Çalışanların işten ayrılma niyetlerinin düşük olması, güvene dayalı örgüt çalışan ilişkisi karşılıklı beklentilerin karşılanmasını artıracak, işten ayrılmanın işletmeye getirdiği maliyetleri düşürecektir. Bu çalışmanın literatüre olan katkısının artırılması adına, elde edilen veriler ışı̆̆ında çalışmanın sınırları artırılarak, çalışma nitel verilerle zenginleştirilmelidir.

\section{Kaynakça}

Arthur, M. B., Lawrence, B. S. (1984). Perspectives on environment and career: An introduction. J. Organiz. Behav., 5, s.1-8. doi:10.1002/job.4030050102

Aydın Göktepe, E. (2017). Relationship Between New Career Attitudes, Perceived Supervisor Support and Work Engagement: A Research, Demirdizen Çevik, D. Ve Taşkıran G., (Ed.). Current Debates in Labour Economics, Demography \& Gender Studies,„ö Volume 7, IJOPEC Publication, 43-64

Beatty E. Sheron, Lynn R.Kahle, Pamela Homer, Shekhor Misra. (1985). Alternative Measurement Approaches to Consumer Values: The List of Values and The Rokeach Value Survey, Psychology\&Marketing, Vol:2,3, 181-200. https://doi.org/10.1002/mar.4220020305

Becker, G. M., \& McClintock, C. G. (1967). Value: Behavioral decision theory. Annual Review of Psychology, 18, 239-286. http://dx.doi.org/10.1146/annurev.ps.18.020167.001323 
Bhanthumnavin, D., (2003). "Perceived social support from Supervisor and group members' psychological and situational characteristics as predictors of subordinate performance in Thai work units." Human Resource Development Quarterly, Vol.14, 74-97. https://doi.org/10.1002/hrdq.1051

Bollen, K.A. (1989). Structural Equations with Latent Variables, Wiley: New York.

Conklin, Mark H., Desselle S. P. (2007). "Job Turnover Intentions Among Pharmacy Faculty", American Journal of Pharmaceutical Education, 71(4): 1-9. https://doi.org/10.5688/aj710462

Eisenberger, R., Huntington, R., Hutchison, S. ve Sowa, D., (1986). Percieved organizational support. Journal of Applied Psychology, 71(3), 500- 507. https://doi.org/10.1037/00219010.71.3.500

Fornell, Claes and D.F. Larcker (1981). "Evaluation Structural Equations Models with Unobservable Variables and Measurement Error," Journal of Marketing Research, Vol. 18, No.1, Feb., 1981, pp.39-50. https://doi.org/10.1177/002224378101800104

Granrose, C. S.(1995). “A Model of Organizational Careers in National Contexts”, Journal of Asian Business, Vol.11, No.3, 5.

Gutman Jonathan. (1982). A Means-end Chain Model Based on Consumer Categorization Processes, Journal of Marketing. Vol:56, Spring; ss.60-72. https://doi.org/10.1177/002224298204600207

Hair, J., F., Black, W.,C., Babin, B.,J., \& Anderson, R.E. (2009). Multivariate data analysis a global perspective. (7th edt.), Upper Saddle River, NJ: Prentice-Hall.

Hardy C.C., (1987). The Blue Chip Investment Strategy: Quality, Value and Timing for Income Appreciation, New York, F Watts.

Jöreskog, K.,G., \& Sörbom, D. (1996). LISREL 8: User's reference guide. Scientific Software International,Chicago.

Kağıtçıbaşı, Ç. \& Kuşdil, E. (2000). “Türk Öğretmenlerin Değer Yönelimleri ve Schwartz Değer Kuramı”, Türk Psikoloji Dergisi, 29-80.

Kahle Lynn R. (1983). Social Values and Social Change, Adaptation to Life in America. NewYork,Praeger. ABD.

Kahle Lynn R. (1985). Social Values in The Eighties: A Special Issue, Psychology\&Marketing. Winter;2,4; ss.231.

Kang, H. J. (Annette), Gatling A., Kim, J. (Sunny) (2015). "The Impact of Supervisory Support on Organizational Commitment, Caree Satisfaction, and Turnover Intention for Hospitality Frontline Employees", Journal of Human Resources in Hospitality \& Tourism, 14(1): 68-89. https://doi.org/10.1080/15332845.2014.904176

Kassing, J. W., Nicole M. P., Carmen C. G., Curtis A. M. (2012). "Dissent Expression as an Indicator of Work Engagement and Intention to Leave", Journal of Business Communication, 49(3): 237-253. https://doi.org/10.1177/0021943612446751

Keller, L. M. (1992). "Work Values: Genetic and Environmental Influences", Journal of Applied Psychology, 77(1).

Kim, Young-Gook, Soo Kim, Jung-Lim Yoo (2012). "Travel Agency Employees' Career Commitment and Turnover Intention During the Recent Global Economic Crisis", The $\begin{array}{llll}\text { Service Industries } & \text { Journal, } & \text { 32(8): }\end{array}$ https://doi.org/10.1080/02642069.2010.545393 
Kinnier, R., J. Kernes, L. ve Dautheribes, T.M. (2000). "A Short List of Universal Moral Values". Counseling and Values, 45(1): 4-17. https://doi.org/10.1002/j.2161-007x.2000.tb00178.x

Kraimer, M. L., Wayne, S. J., (2004). "An Examination of Perceived Organizational Support as a Multidimensional Construct in the Context of an Expatriate Assignment", Journal of Management, Vol.30, No.2, 209. https://doi.org/10.1016/j.jm.2003.01.001

Kuçuradi, İ. (2013). İnsan ve Değerleri, 5. Bask1, Ankara: Türkiye Felsefe Kurumu.

Küçükaltan G., Ergin G., (2009). Otel İşletmelerinde Yöneticilerin Dışsal Krizlere Yaklaşımlarına Yönelik Bir Araştırma, Trakya Üniversitesi Sosyal Bilimler Dergisi, Aralık, Cilt 11, Sayı 2. https://doi.org/10.17336/igusbd.308247

Matthews R, Bulger C.A., Barnes-Farrel J. L., (2009). "Work social supports, role stressors and work-family conflict: The moderating effects of age", Journal of Vocational Behavior ,Vol.76, No.1, 78-90. https://doi.org/10.1016/j.jvb.2009.06.011

Meydan, C, H. (2011). Yapısal Eşitlik Modellenmesi Amos Uygulamaları. Birinci Baskı. Ankara: Detay Yayınc1lik, s.182. 37.

Mobley, W. H., Homer, S. 0., \& Hollingsworth, A. T. (1978). An evaluation of precursors of hospital employee turnover. Journal of Applied Psychology, 63, 408-414. https://doi.org/10.1037/0021-9010.63.4.408

Mobley, W., Griffith, R., Hand, H., Meglino, B. (1979). Review and conceptual analysis of the employee turnover process. Psychological Bulletin, Vol: 86, s. 493-522

Odabas1, Y. (2002). Tüketici Davranısı. Kapital Medya Hizmetleri AS., İstanbul.

Parameswaran, B. Srikanth ve L Gurunathan, (2013). "Interactional Justice and Pharmacy Faculty", American Journal of Pharmaceutical Education, 71(4): 1-9.

Pitts, R., Canty, E.A., Tsalikis, J. (1985). "Eploring The Impact of Personal Values on Socially Oriented Communications", Psychology \&Marketing, Vol:2,4,267-278. https://doi.org/10.1002/mar.4220020406

Prakash, V. J., Munson, M. (1985). Values, Expectations From The Marketing System and Product Expectations, Psychology\&Marketing. Vol:2, No:4, ss.279-296. https://doi.org/10.1002/mar.4220020407

Raykov, T., Marcoulides, G.A. (2006). A first course in structural equation modeling. Mahwah, NJ: Lawrence Erlbaum Associates. https://doi.org/10.1177/1094428107308985

Rhoades, L., Eisenberger, R. (2002). "Perceived Organizational Support: A Review of the Literatüre", Journal of Applied Psychology, Vol.87, No.4, 698-714. https://doi.org/10.1037/0021-9010.87.4.698

Rokeach, M. (1973). The nature of human values. New York: Free Press.

Rooney, J. A., Gottlieb, B. H., (2007). "Develpoment and initial validation of a measure of supportive and unsupportive managerial behaviors", Jounal of Vocational Behavior, Vol.71, No.2, 187. https://doi.org/10.1016/j.jvb.2007.03.006

Rousseau, D., M. Parks, J. M. (1992). “The Contracts of Individuals and Organizations”, Research in Organizational Behavior, Vol.15, 1-43.

Schermelleh-Engel, K., \& Moosbrugger, H. (2003). Evaluating the fit of structural equation models: Tests of significance and descriptive goodness-of-fit measures. Methods of Psychological Research Online, 8 (2), 23-74. 
Shao, Yu-Lin. (2002). An Exploratory Examination of The Impact of Personal Values on Sport Consumption Preferences and Behavior: A Cross-Cultural Study, Ohio State University, Phd Dissertation, USA. UMI.

Solomon, M., R. (1996). Consumer Behavior, Third Edition. Prentice Hall International Editions, USA.

Tekleab, A., G., Bartol, K. M., Wei L. (2005). "Is It Pay Levels or Pay Raises That Matter to Fairness and Turnover?", Journal of Organizational Behavior, 26(8): 899-921. https://doi.org/10.1002/job.352

Thompson, C. A., Beauvais, L. L., Lyness, K. S., (1999). "When Work-Family Benefits Are Not Enough: The Influence of Work-Family Culture on Benefit Utilization, Organizational Attachment, and Work-Family Conflict", Journal of Vocational Behavior, Vol. 54, No.3, 393. https://doi.org/10.1006/jvbe.1998.1681

Tokgöz, N. (2011). Örgütsel Sinizm, Örgütsel Destek ve Örgütsel Adalet İlişkisi: Elektrik Dağıtım İşletmesi Çalışanları Örneği. Eskişehir Osmangazi Üniversitesi İIBF Dergisi, Cilt:6, No:2, 363-387. https://doi.org/10.17153/oguiibf.439835

Waldroop, J. ve Butler, T.(2011). Çalışanları Elde Tutmak. (Çeviri: M. Inan). Istanbul: Optimist Yayınları. 